\title{
ASPECTOS DE UNA RELACIÓN TRIANGULAR EN LA SUBCONTRATACIÓN LABORAL: NATURALEZA JURÍDICA Y ALCANCES DE LA OBLIGACIÓN DE CUIDADO DE LA EMPRESA PRINCIPAL RESPECTO DE TRABAJADORES DE CONTRATISTAS Y SUBCONTRATISTAS QUE LABORAN EN SU OBRA O FAENA*
}

\author{
ASPECTS OF A TRIANGULAR RELATIONSHIP IN LABOUR \\ SUBCONTRACTING: LEGAL NATURAL AND SCOPE OF THE DUTY \\ OF CARE OF THE PRINCIPAL COMPANY WITH RESPECT TO \\ EMPLOYEES OF CONTRACTORS AND SUBCONTRACTORS THAT \\ WORK IN HIS WORK OR LABOR
}

\author{
Paula Eugenia Donoso Vergara**
}

\begin{abstract}
RESUMEN: Este trabajo trata sobre el tipo de relación que surge entre los actores que intervienen en la subcontratación laboral, enfocando el análisis en la obligación de cuidado que la ley asigna directamente a la empresa principal respecto de trabajadores subcontratados que laboran en su obra o faena. En dicho marco, el contrato de trabajo que une al contratista o subcontratista con el trabajador expande sus efectos hacia la empresa principal, un tercero que no es parte de la relación laboral, pero que adquiere obligaciones propias e inmediatas en materia de salud y seguridad, constituyéndose en un deudor más de dicha obligación ante el trabajador. La configuración de una relación trilateral laboral en este aspecto, se examina a partir de las definiciones relativas a la naturaleza jurídica y alcances de la obligación de cuidado; las responsabilidades que se atribuyen a la empresa principal y la aplicación de los principios del Derecho del Trabajo en tales determinaciones.
\end{abstract}

Palabras clave: Subcontratación laboral, obligación de cuidado, empresa principal, trilateralidad laboral

ABSTRACT: This article discusses the type of relation that it arises between the actors who intervene in the labor subcontracting, focusing the analysis in the safety obligation that the law assigns directly to the principal company respect of subcontracted employees who work in his work or task. The contract of work that joins the contractor or subcontractor with the employee expands his effects towards the principal company, a third side that is not a part of the labor relation, but that acquires own and immediate obligations as for health and safety, being constituted in one more debtor of the above mentioned obligation before the employee. The configuration of a trilateral labor relation in this aspect, examines from the definitions relative to the juridical nature and scopes of the safety obligation; the responsibilities that assume to the principal company and the application of the principles of the Labor law in such determinations.

Keys words: Labor subcontracting, safety obligation, principal company, trilateral labor relation

\footnotetext{
${ }^{*}$ Este artículo corresponde a una nueva versión del Seminario de Título presentado por la autora en septiembre de 2014 para optar al grado de Magíster en Derecho del Trabajo y Seguridad Social impartido en conjunto por la Universidad de Talca (Chile) y la Universidad de Valencia (España), cuya dirección estuvo a cargo del profesor Rodrigo Palomo Vélez.

** Abogada, Licenciada en Ciencias Jurídicas y Sociales por la Universidad de Chile. Magíster en Ciencia Política por la misma Universidad. Magíster en Derecho del Trabajo y de la Seguridad Social por la Universidad de Talca (Chile) y la Universidad de Valencia (España). Con especialidad en Derecho Administrativo y Nueva Justicia Laboral. Ex Subdirectora de la División de Organizaciones Sociales del Ministerio Secretaría General de Gobierno (período 2008-2010). Ha sido Asesora en Materias Legislativas del Ministerio Secretaría General de Gobierno (1999-2008), participando en la elaboración denumerosos proyectos de ley.
} 


\section{INTRODUCCIÓN}

El trabajo en régimen de subcontratación plantea diversos problemas jurídicos asociados a las especiales condiciones en que se desarrolla el contrato de trabajo, en el marco de un vínculo jurídico complejo que se materializa en una doble relación: por una parte, un contrato civil o comercial que involucra a la empresa principal y a la contratista y, por otra, un contrato de trabajo que liga al empleador -contratista o subcontratista- con el trabajador. En este contexto -dentro del ordenamiento jurídico chileno- surge la interrogante relativa a las obligaciones que se generan para la empresa principal a consecuencia del contrato de trabajo existente entre el contratista y el trabajador, pues se trata de un tercero ajeno a la relación laboral, pero que se encuentra jurídicamente obligado y debe responder ante eventuales incumplimientos.

Una de las obligaciones que la ley impone directamente a la empresa principal se refiere al deber de protección respecto de los trabajadores subcontratados. Sobre este asunto, cabe preguntarse: ¿qué tipo de relación se configura, respecto de este deber, entre las partes que intervienen en el trabajo en régimen de subcontratación, entre la empresa principal, la contratista y el trabajador? En este mismo sentido y más concretamente: ¿se trata de una vinculación de carácter laboral para ambas empresas respecto del trabajador, o existe un vínculo civil o de otro tipo para la empresa principal? ¿Se configura en este aspecto una relación de carácter triangular, laboral, entre las partes intervinientes? ${ }^{1}$.

La idea central que aquí se plantea es que el trabajo en régimen de subcontratación, en el ordenamiento jurídico chileno, se caracteriza por una relación de doble vínculo. De un lado, un contrato civil o comercial entre la empresa principal y la contratista y, de otro, un contrato de trabajo entre la empresa contratista y el trabajador, sin que en principio exista relación inmediata entre la empresa principal y el trabajador. No obstante, la obligación de cuidado que impone la ley a la empresa principal -derivada del contrato de trabajo existente entre el contratista y el trabajador- configuraría, al menos en este aspecto, una relación triangular de tipo laboral, quedando el trabajador ligado, directamente, tanto a su empleador como a la empresa principal.

De acuerdo con lo anterior, en este trabajo se indaga acerca de la naturaleza jurídica de la obligación de cuidado que se impone a la empresa principal en el marco del contrato de trabajo existente entre la empresa contratista y el trabajador. En este punto, además de establecer si se trata de una obligación laboral o civil, resulta importante conocer de dónde emana la obligación: de la ley, del contrato de trabajo o del vínculo civil o comercial establecido con el contratista, o bien, de una combinación de fuentes. Asimismo, y en cuanto al régimen de responsabilidad que se establece, se aborda el tipo de responsabilidad que genera para la empresa principal el incumplimiento de la obligación de cuidado que le impone el artículo 183 E del Código del Trabajo respecto a los trabajadores de empresas contratistas o

\footnotetext{
${ }^{1}$ En este trabajo se analiza la relación existente entre la empresa principal, la empresa contratista o subcontratista y el trabajador, respecto del deber de protección, sin detenerse en las distinciones entre los conceptos jurídicos de relación, vinculación y obligación. No obstante corresponder, en estricto sentido, a nociones jurídicas diversas, se acudirá a todas ellas para los efectos de dar respuesta a la interrogante relativa a la existencia o no una relación trilateral laboral en este aspecto, por estimar que tales diferenciaciones no afectan el análisis de fondo.
} 
Paula E. Donoso Vergara / Aspectos de una relación triangular en la subcontratación laboral: Naturaleza jurídica y alcances de la obligación de cuidado de la empresa principal respecto de trabajadores de contratistas y subcontratistas que laboren en su obra o

subcontratistas que laboran en su obra o faena. Si se trata de una responsabilidad civil o laboral $\mathrm{y}$, en relación con la forma en que ésta se hace efectiva, si es simplemente conjunta, solidaria o subsidiaria. En el sentido antes indicado también se analiza la intervención de los principios del Derecho del Trabajo en la determinación de las específicas exigencias y el grado de responsabilidad que se impone a la empresa principal en cuanto al cumplimiento del deber de protección.

De tal modo, se aborda un problema específico del trabajo en régimen de subcontratación, concentrándose en un aspecto de la relación que se configura entre las partes intervinientes. Dicho aspecto se refiere el vínculo que se establece respecto al deber de protección impuesto a la empresa principal, en relación con los trabajadores de sus contratistas y subcontratistas. Pero, al mismo tiempo, se trata de una discusión más amplia, relativa a las definiciones generales sobre el tipo de relación existente entre las partes en el marco de la subcontratación laboral y la aplicación de los principios en la solución de los problemas jurídicos asociados a las mismas.

\section{TRABAJO EN RÉGIMEN DE SUBCONTRATACIÓN EN EL MARCO DE LA DESCENTRALIZACIÓN PRODUCTIVA Y SUS REPERCUSIONES EN LA CONTRATACIÓN LABORAL}

\subsection{EL TRABAJO EN RÉGIMEN DE SUBCONTRATACIÓN COMO UNA MANIFESTACIÓN DE LA DESCENTRALIZACIÓN PRODUCTIVA}

La figura de la subcontratación laboral emerge como una manifestación de la externalización o descentralización productiva. Es un fenómeno que se explica a partir de las diversas formas de organización empresarial, con impacto a nivel mundial y ostensibles repercusiones en el ámbito del Derecho del Trabajo. Los efectos de la descentralización productiva en esta esfera se presentan tanto en su nivel estructural como en el área de regulación de las relaciones laborales. Se plantea en este escenario, con notoria recurrencia, un deterioro en las condiciones de trabajo, producto del distanciamiento del trabajador del centro de decisión empresarial, generando muchas veces un contexto de precarización laboral. En este mismo sentido, se cuestionan las estructuras básicas normativas del Derecho del Trabajo, sustentadas en los conceptos de empleador, trabajador y organizaciones de trabajadores, y se pone en entredicho, al mismo tiempo, la efectividad de los instrumentos jurídicos tendientes a la protección de los derechos laborales ${ }^{2}$.

Las diversas fisonomías que adquiere la descentralización productiva dan cuenta, en mayor o menor grado, de tales consecuencias. La manera en que se ha reorganizado la empresa, mediante la tercerización de servicios y funciones -en la subcontratación y en el suministro de trabajadores- así como a través de la fragmentación de la misma en los grupos de empresas, han significado un cambio profundo en el mundo del trabajo, en el sentido de hacerlo más complejo y susceptible al fraude y a la vulneración de las normas laborales. Por este motivo, la regulación de las distintas figuras de la descentralización empresarial o productiva, desde el ámbito laboral, en los diferentes sistemas jurídicos, se ha transformado en

${ }^{2}$ ROJAS (2011) pp. 15-17. 
Paula E. Donoso Vergara / Aspectos de una relación triangular en la subcontratación laboral: Naturaleza jurídica y alcances de la obligación de cuidado de la empresa principal respecto de trabajadores de contratistas y subcontratistas que laboren en su obra o

un instrumento central y necesario para morigerar los efectos negativos que estas formas de reorganización pueden ocasionar.

Así, y según se ha advertido, el fenómeno de la descentralización productiva, presente a nivel mundial desde hace varias décadas -pero con un especial impulso en las últimas dos- toca en lo medular a la estructura de la empresa y a su vinculación con otras empresas con las que se generan relaciones civiles o comerciales ${ }^{3}$. No obstante, las secuelas desde el punto de vista jurídico-laboral son múltiples y de diversa envergadura. Estas repercusiones se explican en parte por la particular sensibilidad del Derecho del Trabajo ante los cambios sociales y económicos ${ }^{4}$. Dentro de este marco, se afecta una de sus instituciones básicas, como es la contratación laboral, la que ve alterada su estructura principal de relaciones y de los elementos que la componen.

\subsection{EL TRABAJO EN RÉGIMEN DE SUBCONTRATACIÓN COMO UNA FORMA DE ATIPICIDAD DEL CONTRATO DE TRABAJO}

El trabajo externo -que tiene lugar en las diversas manifestaciones de la descentralización productiva- ha sido analizado en el escenario antes descrito, como una forma de atipicidad del contrato de trabajo ${ }^{5}$. La característica central de este tipo de relación laboral se enmarca en un contexto empresarial donde la antigua empresa cede ante una empresa moderna que busca competitividad, flexibilidad y una mayor eficacia en la gestión. En este marco, la empresa se transforma desde el punto de vista organizativo: reduce su núcleo duro de trabajadores y genera alrededor del mismo un segundo nivel de trabajadores con una vinculación habitualmente más precaria. Estos últimos laboran para la empresa, pero desde el punto de vista formal se encuentran al margen de ella, generalmente vinculados a través de un intermediario, contratista o subcontratista. Se distingue así, en esta organización empresarial, entre trabajadores "internos" y trabajadores "periféricos".

De este modo, el tipo de relación laboral que emerge para este segundo nivel de trabajadores se inscribiría en la categoría de ocupación o empleo atípicos. Se trata de modalidades de contratación laboral que no se encasillan en lo que se ha definido como el "modelo de relación normal", por no corresponder a los cánones tradicionales en cuanto a los diversos elementos que caracterizan a la relación laboral: duración y continuidad; lugar de prestación de servicios; tiempo de trabajo, son algunos elementos que, en términos generales, escapan al modelo arquetípico de trabajo subordinado regulado por el ordenamiento jurídico laboral ${ }^{7}$. De modo tal que el contrato de trabajo atípico se definiría por la ausencia de alguno de los elementos que caracterizan al empleo típico ${ }^{8}$. Al mismo tiempo, la relación que se configura en esta zona periférica en la que se ubican habitualmente los trabajadores subcontratados, como ya se ha dicho, se genera muchas veces en situaciones de mayor precariedad o con un estándar más bajo de cumplimiento de las obligaciones laborales. En tal

\footnotetext{
3 ERMIDA Y COLOTUZZO (2009).

4 ERMidA Y COLOTUZZO (2009).

${ }^{5} \operatorname{Delgue}(2000)$ p. 189.

${ }^{6}$ Delgue (2000) p. 191.

${ }^{7}$ CAAMAÑo (2005) pp. 25-53.

${ }^{8}$ Para una revisión sobre las distinciones entre contrato de trabajo típico, atípico y precario: ROJAS (2004) pp. 1920.
} 
Paula E. Donoso Vergara / Aspectos de una relación triangular en la subcontratación laboral: Naturaleza jurídica y alcances de la obligación de cuidado de la empresa principal respecto de trabajadores de contratistas y subcontratistas que laboren en su obra o

sentido, es preciso distinguir entre el trabajo precario y el atípico. Se ha sostenido que la diferencia entre ambos radica básicamente en que mientras el primero se encuentra al margen, o en zonas fronterizas del Derecho del Trabajo, y lo caracterizan elementos tales como inestabilidad, inseguridad e insuficiencia en las condiciones de trabajo y protección de la seguridad social, el segundo refiere a ocupaciones de carácter laboral que se prestan bajo vínculo de subordinación y dependencia, amparados en mayor o menor medida por el Derecho del Trabajo; pero no corresponden al tipo normal ${ }^{9}$.

Ahora bien, en lo que atañe específicamente a la subcontratación laboral, como forma de contratación laboral atípica y en muchas ocasiones precaria, parte de la doctrina nacional considera que ésta sólo se presenta en la subcontratación de servicios personales, identificándola con el suministro de trabajadores, y no así en la subcontratación de servicios materiales ${ }^{10}$. Esto se explicaría, desde este punto de vista, por el hecho de que en esta última clase de subcontratación no se presentaría una variación al modelo de contrato individual de trabajo habitual, ya que sus elementos estarían presentes en la relación laboral que se da entre el empleador - contratista o subcontratista- y cada trabajador, y sin que exista una vinculación directa con la mandante. En tal caso, según se ha sostenido, los problemas para los trabajadores serían menores que en la situación del suministro de trabajadores, ya que en la subcontratación éstos se limitarían a asegurar el cumplimiento efectivo de la ley y a equiparar las condiciones de salario entre los trabajadores subcontratados y los contratados directamente por la empresa principa ${ }^{11}$. Vale decir, las dificultades en estos casos se asociarían a condiciones más o menos favorables de contratación y condiciones de cumplimiento del contrato de trabajo. Al respecto, y compartiendo la necesidad de reconocer las diferencias existentes entre ambas figuras -las que se abordarán con mayor detalle en el acápite siguiente- estimamos que en ambas es posible advertir formas de contratación laboral que se alejan del concepto tradicional regulado por el ordenamiento jurídico laboral. Teniendo además a la vista la realidad concreta en la que se desarrolla el trabajo en régimen de subcontratación, ésta da cuenta de una estructura de relaciones que deja a los trabajadores tercerizados al margen del eje central de toma de las decisiones que les afectan directamente en cuanto a las condiciones de trabajo y salariales, rompiendo de esta manera con el molde habitual en que tiene lugar la relación laboral.

\subsection{DIFERENCIAS ENTRE DOS MODALIDADES DE TERCERIZACIÓN: SUBCONTRATACIÓN LABORALY SUMINISTRODETRABAJADORES}

La subcontratación laboral y el suministro de trabajadores corresponden a dos modalidades de externalización que presentan características, desarrollos y regulaciones muy distintas, pese a que forman parte de una misma categoría jurídica. Así, atendiendo a sus definiciones, la primera figura se refiere al vínculo que establecen dos empresas, donde una empresa, denominada principal o mandante, encarga a otra -contratista o subcontratista- la producción de bienes o la prestación de servicios, para que esta segunda empresa los ejecute por su cuenta y riesgo y con sus propios trabajadores; en cambio la segunda figura -el suministro de trabajadores- establece una vinculación entre dos empresas, la usuaria y la

\footnotetext{
${ }^{9}$ CAAMAÑo (2005) pp. 25 - 53.

10 CAAMAÑO (2005) pp. 25 - 53.

11 UGARTE (2011) p. 95.
} 
Paula E. Donoso Vergara / Aspectos de una relación triangular en la subcontratación laboral: Naturaleza jurídica y alcances de la obligación de cuidado de la empresa principal respecto de trabajadores de contratistas y subcontratistas que laboren en su obra o faena. empresa suministradora, pero esta vez con el objeto de que la segunda ponga a trabajadores a disposición de la primera, para que éstos ejecuten una actividad laboral determinada.

En este contexto, es posible trazar varias diferencias que particularizan a ambas figuras. En efecto, uno de los elementos centrales de distinción está dado por el ejercicio del poder de dirección. En la subcontratación, éste debe ser ejercido por la empresa contratista o subcontratista respecto de sus trabajadores, mientras que en el suministro de trabajadores dicho poder es ejercido directamente por la empresa usuaria, respecto a los trabajadores que la empresa suministradora pone a su disposición ${ }^{12}$. En cuanto al objeto del contrato civil o comercial entre las empresas, en la subcontratación laboral éste se refiere a la ejecución de una obra o la prestación de un servicio, en el suministro; en cambio, el objeto específico tiene que ver con la puesta a disposición de trabajadores, con el suministro de mano de obra ${ }^{13}$.

Otro elemento importante que vale la pena destacar se relaciona con el desarrollo de estas modalidades de tercerización y del tratamiento normativo de las mismas. Si bien la subcontratación, como lo advertimos antes, es una figura presente desde tiempos antiguos, ha sido en las últimas décadas cuando ha adquirido mayor significación, transformándose en una forma habitual y perfectamente lícita de desarrollo de la actividad empresarial, con incidencias en el mundo laboral, que han exigido una particular regulación en los distintos sistemas jurídicos. No ha sucedido lo mismo con el suministro de trabajadores, ya que corresponde a una figura considerada por los distintos ordenamientos, hasta hace algunas décadas, como una modalidad ilícita de desarrollo de trabajo externo. La intermediación de mano de obra estaba prohibida y era resistida por el Derecho del Trabajo, precisamente por constituir un modo anómalo y atentatorio contra los derechos laborales ${ }^{14}$. No obstante, en los últimos tiempos la fuerza de los acontecimientos llevó a los distintos sistemas jurídicos a la regulación de esta figura, estableciendo de cierta manera una normativa más estricta para el desarrollo de la actividad empresarial cuyo objeto es el suministro de trabajadores. La legislación chilena no ha estado ajena a esta realidad. Así las cosas, la Ley $\mathrm{N}^{\circ} 20.123$, del año 2006, hace una clara distinción entre ambas figuras, incorporando una nueva y detallada regulación para el suministro de trabajadores; norma específicamente la forma de funcionamiento de las empresas suministradoras; establece un registro y la obligación de garantía, y, al mismo tiempo, límites para acudir al suministro de trabajadores, tanto desde el punto de vista temporal como de las causas que lo justifican ${ }^{15}$.

Ahora bien, un aspecto de gran interés para esta investigación se refiere a los vínculos que se crean entre los intervinientes en la subcontratación laboral y en el suministro de trabajadores. En el primer caso, se ha afirmado que podría importar tanto una relación laboral "triangular" -cuando la relación es entre empresa principal, contratista y trabajador- como "cuadricular" de trabajo, cuando interviene además una empresa subcontratista. Diferente es el suministro de trabajadores, porque sólo podría configurarse una relación estrictamente triangular, en la que participan la empresa usuaria, la suministradora y el trabajador ${ }^{16}$.

\footnotetext{
12 LiZAMA Y UGARTE(2009)p. 9.

13 LiZAMA Y UGARTE (2009) p. 9.

14 Véase: ROJAS (2011) p. 31.

15 Ver artículos 183 -F a 183 - AB del Código del Trabajo.

${ }^{16}$ LIZAMA Y UGARTE (2009) p. 10.
} 
Paula E. Donoso Vergara / Aspectos de una relación triangular en la subcontratación laboral: Naturaleza jurídica y alcances de la obligación de cuidado de la empresa principal respecto de trabajadores de contratistas y subcontratistas que laboren en su obra o

\subsection{RELACIONES LABORALES TRIANGULARES EN LA SUBCONTRATACIÓN LABORAL Y EN EL} faena. SUMINISTRODETRABAJADORES

De cualquier manera, y habiéndose efectuado las distinciones previas, es posible advertir que se habla de la existencia de relaciones laborales triangulares en referencia a aquellos vínculos jurídicos en que confluyen tres actores: una empresa que contrata los servicios a otra empresa, a quien encarga la ejecución de una actividad concreta que es ejecutada por los trabajadores de la segunda empresa, quienes en definitiva quedan situados entre ambas ${ }^{17}$. Según parte de la doctrina, esta denominada trilateralidad laboral puede revestir básicamente dos formas: la subcontratación laboral y el suministro de trabajadores ${ }^{18}$, $\sin$ distinguir mayormente entre ambas modalidades, en cuanto al carácter triangular de la relación que se configura, además de la ya señalada. No obstante, en lo que se refiere específicamente a la subcontratación laboral, otra parte de la doctrina nacional advierte que no estaríamos en presencia de una relación triangular de trabajo. Esto, teniendo en cuenta que en la regulación del trabajo en régimen de subcontratación es el contratista o subcontratista el único empleador, quien realiza por su cuenta y riesgo la actividad encomendada y con trabajadores que están bajo su dependencia y subordinación ${ }^{19}$.

De esta manera, se discute en la doctrina nacional la presencia de una relación laboral triangular en el caso de la subcontratación laboral. En el suministro de trabajadores no cabría mayor duda al respecto y la triangulación sería clara y evidente. En lo que toca a la subcontratación laboral, uno de los elementos considerados para definirla, y que es común también al suministro, está dado por la responsabilidad legal que se atribuye a quien se beneficia con el trabajo ejecutado por los trabajadores del tercero externo ${ }^{20}$. Para aquella parte de la doctrina que no reconoce la existencia de una relación triangular de trabajo en la subcontratación laboral, ese elemento, si bien permite afirmar la configuración de un vínculo triangular de carácter residual ${ }^{21}$, éste sería indirecto y sólo acotado a este elemento de responsabilidad en el cumplimiento de las obligaciones laborales.

Estas consideraciones generales respecto al trabajo en régimen de subcontratación plantean la necesidad de mirar con detención cada uno de los aspectos que dicho tipo de contratación involucra, para determinar la existencia o no de una vinculación trilateral. Uno de estos elementos es el ya señalado, relacionado con la responsabilidad de la empresa principal. Pero, desde el punto de vista de las obligaciones que se le imponen interesa, en esta parte, un aspecto regulado específicamente por el Código del Trabajo chileno, relativo al deber de protección impuesto a la empresa principal en el marco de la subcontratación laboral. En este caso específico se impone una responsabilidad directa a la empresa principal, obligada por tanto a adoptar medidas concretas y específicas para proteger eficazmente la vida y salud de los trabajadores, incluidos los contratados y subcontratados. Determinar la envergadura y naturaleza de esta obligación resulta relevante para los efectos de configurar el mapa de relaciones presentes en la subcontratación laboral.

\footnotetext{
17 Véase: UGARTE (2011) p. 93.

18 UGARTE (2011) p. 94.

${ }^{19}$ RoJAS (2011) p.71.

20 SALA et al. (2011) p. 99.

${ }^{21}$ RoJas(2011)p. 21.
} 
Paula E. Donoso Vergara / Aspectos de una relación triangular en la subcontratación laboral: Naturaleza jurídica y alcances de la obligación de cuidado de la empresa principal respecto de trabajadores de contratistas y subcontratistas que laboren en su obra o

3.NATURALEZA JURÍDICA Y ALCANCES DE LA OBLIGACIÓN DE CUIDADO QUE SE IMPONE A LA EMPRESA PRINCIPAL EN LA SUBCONTRATACIÓN

\section{LABORAL}

\subsection{EL DEBER DE PROTECCIÓN EN EL TRABAJO: UNA OBLIGACIÓN DIRECTA PARA LA EMPRESA PRINCIPAL EN LA SUBCONTRATACIÓN LABORAL}

En el ordenamiento jurídico chileno la regla general es que los derechos y obligaciones que emanan del contrato de trabajo celebrado entre el trabajador y la empresa contratista afectan únicamente a las partes que en él intervienen, sin que exista vinculación jurídica, en esta esfera, para la empresa principal. No obstante, una excepción a esta norma es la obligación directa que el artículo 183 E del Código del Trabajo impone a la empresa principal respecto al deber de protección de todos los trabajadores que laboran en su obra o faena, sean estos propios o subcontratados. En este caso, la empresa principal no sólo debe responder ante los eventuales incumplimientos de la empresa contratista o subcontratista, sino que ella se encuentra jurídicamente obligada a ejecutar ciertos actos y adoptar determinadas medidas respecto de los trabajadores subcontratados. Esto conforme a la obligación general de seguridad que el artículo 184 del Código del Trabajo impone al empleador, y a las normas legales y reglamentarias de desarrollo ${ }^{22}$.

Sobre esta materia, es preciso tener en cuenta sus alcances, dado que la obligación directa de la empresa principal remite a ese deber general de protección de dicho artículo 184 del Código del Trabajo. Según se ha señalado, esta obligación conforma una auténtica garantía de seguridad que, al tiempo de constituir una obligación en sí, se instala como una máxima que debe guiar la aplicación de las normas de prevención en materia de salud y seguridad en el trabajo $^{23}$. Se atribuye a este deber -también llamado deuda de seguridad- un imperativo que acciona como una fuerza integradora y un principio de interpretación que tiene que ser considerado en toda su magnitud al momento de establecer los alcances de la obligación de cuidado, que va más allá de la adopción de las medidas preventivas concretas exigidas ${ }^{24}$. De esta manera, la aplicación del deber general de seguridad contenido en el artículo 184 del Código del Trabajo, al imponer una obligación de protección eficaz de la vida y salud de los trabajadores, exige al obligado, además del cumplimiento de normas preventivas establecidas en la ley y normas técnicas que correspondan, la adopción de todas las medidas que se requieran para garantizar la eficacia de la protección y una obligación de actuar diligente para el deudor.

Supuesto lo anterior, en lo que toca a la obligación de cuidado o seguridad que pesa sobre la empresa principal, tratándose de los trabajadores que laboran en su obra o faena, es necesario determinar su contenido y límites. Sobre el particular, se ha dicho que con la Ley $\mathrm{N}^{\circ}$ 20.123 operó un cambio en el eje normativo en materia de salud y seguridad, en lo que dice relación con los trabajadores contratados bajo régimen de subcontratación ${ }^{25}$. En tal sentido, se establece a la faena como eje central de la responsabilidad en estas materias, y consecuentemente con

\footnotetext{
22 RoJAs (2011) p. 79.

23 NúÑEZ (2013) p. 85.

24 NúÑEZ (2013) p. 85.

${ }^{25}$ MELIS Y SÁEZ (2009) p. 197.
} 
Paula E. Donoso Vergara / Aspectos de una relación triangular en la subcontratación laboral: Naturaleza jurídica y alcances de la obligación de cuidado de la empresa principal respecto de trabajadores de contratistas y subcontratistas que laboren en su obra o

ello se constituye al dueño de la faena o empresa principal también en obligado, atendidas sus efectivas "posibilidades de control y prevención", aun cuando en esta fórmula ya operaba en parte, con las obligaciones del artículo $3^{\circ}$ del D.S. $\mathrm{N}^{\circ} 594$ del Ministerio de Salud. ${ }^{26}$ No obstante, desde el año 2006, con los cambios introducidos al Código del Trabajo a través de la norma del 183 E y el nuevo artículo 66 bis de la Ley $\mathrm{N}^{\circ} 16.744^{27}$, esta obligación se amplía e intensifica, estableciendo un mandato de cumplimiento directo para la empresa principal.

\subsection{LA OBLIGACIÓN DE CUIDADO EXTENDIDA A LA EMPRESA PRINCIPAL RESPECTO DE LOS TRABAJADORES SUBCONTRATADOS QUE LABORAN EN SU OBRA O FAENA}

En el sentido antes descrito, es posible sostener, como lo ha hecho la Dirección del Trabajo, que con las modificaciones introducidas por la ley 20.123 al deber general de protección del artículo 184 del Código del Trabajo, establecido para trabajadores propios, se adiciona la obligación directa de la empresa principal, respecto de este mismo deber, en relación con los trabajadores que laboran en régimen de subcontratación para ella ${ }^{28}$.

Conforme a la norma del artículo $183 \mathrm{E}$, este deber general de protección que ahora se impone a la empresa principal respecto de los trabajadores bajo régimen de subcontratación se materializa a través de algunas obligaciones específicas, a saber: aquellas establecidas en el nuevo artículo 66 bis de la Ley $\mathrm{N}^{\circ}$ 16.744, reglamentado por el D.S. N ${ }^{\circ} 76$, de 2006, del Ministerio del Trabajo y Previsión Social; y las establecidas en el artículo $3^{\circ}$ del D.S. 594, de 1999, del Ministerio de Salud ${ }^{29}$.

Las medidas específicas que se exigen a la empresa principal en el marco de esta normativa legal que se incorpora apuntan al establecimiento de una serie de instrumentos de prevención y control en materia de salud y seguridad. Estos instrumentos son, básicamente: Sistema de Gestión de la Seguridad y Salud en el Trabajo; Reglamento Especial para Empresas Contratistas y Subcontratistas; Comité Paritario de Faena; y Departamento de Prevención de Riesgos de Faena. ${ }^{30}$ Además, la empresa principal deberá vigilar que el contratista cumpla, a su vez, con las medidas que en materia de salud y seguridad corresponden al empleador directo, de tal modo que si éste no cumple corresponderá a la empresa principal asumir directamente las medidas que aseguren la protección eficaz. Así las cosas, la empresa principal debe asumir sus obligaciones específicas y las compartidas conla empresa contratista ${ }^{31}$.

\footnotetext{
${ }^{26}$ MELIS y SÁEZ (2009) p.197.

${ }^{27}$ Ley que establece normas sobre accidentes del trabajo y enfermedades profesionales.

28 Orden de Servicio No8, de 05 de abril de 2007, Dirección del Trabajo. Imparte criterios de actuación e instrucciones para la aplicación de las normas referidas a la protección de la seguridad y salud en el trabajo de los trabajadores que prestan servicios bajo régimen de subcontratación.

${ }^{29}$ Ídem.

${ }^{30}$ Ídem.

${ }^{31}$ A modo ejemplar, el empleador directo (contratista) debe proporcionar los elementos de protección personal al trabajador (Artículo 53 del D. S. 594, de 1999, Ministerio de Salud) e informar a los trabajadores sobre los riesgos laborales, medidas preventivas y métodos de trabajo, más conocido como derecho a saber (artículo 21 del D.S. 40, de 1969, Ministerio del Trabajo y Previsión Social). La empresa principal, además de las obligaciones que le corresponde asumir como dueña de la obra o faena, deberá vigilar y asegurar el cumplimiento de este tipo de medidas que se exigen al empleador y eventualmente adoptarlas directamente en caso de ser necesario.
} 
Paula E. Donoso Vergara / Aspectos de una relación triangular en la subcontratación laboral: Naturaleza jurídica y alcances de la obligación de cuidado de la empresa principal respecto de trabajadores de contratistas y subcontratistas que laboren en su obra o

Se establece, pues, para la empresa principal, una especial obligación de vigilancia y acciones concretas en materia de salud y seguridad, especialmente cuando se trate de actividades propias de su giro. No obstante, y como se ha señalado antes, la obligación de cuidado no se agota en el cumplimiento de las medidas concretas o acciones de prevención específicamente reguladas por la normativa. Su alcance es mucho mayor y esto nos remite una vez más a la extensión del deber general de protección al que apunta la norma del 183 E y a la determinación de la naturaleza de esta obligación.

\subsection{NATURALEZA Y ALCANCES DEL DEBER DE PROTECCIÓN LABORAL PARA LA EMPRESA PRINCIPAL}

En cuanto a la naturaleza jurídica de la obligación de cuidado que se impone a la empresa principal -en el marco del contrato de trabajo existente entre la contratista y el trabajador- y de acuerdo a lo visto en el acápite anterior, se trata de una obligación de naturaleza laboral. Esta obligación, si bien tiene un origen legal, deriva del vínculo contractual laboral y nace con el contrato de trabajo, que liga al contratista con el trabajador, relacionándolo, a su vez, directamente con la empresa principal.

Sobre esta obligación, su naturaleza y alcances, recientemente la Excma. Corte Suprema se ha pronunciado en un fallo de unificación de jurisprudencia ${ }^{32}$, advirtiendo que la obligación consagrada en el artículo 183 E del Código del Trabajo refiere a una de tipo especial y particular, en materia de higiene y seguridad, que impone al dueño de la obra el deber de protección eficaz de todos los trabajadores que se desempeñen en su obra o faena. No se trata ya de un deber de garante de la obligación de un tercero, sino de una obligación propia que hace responsable a la empresa principal de su propia conducta. La comprensión de esta norma, de acuerdo a esta interpretación, debe ser entendida como una disposición expresa de la ley en protección al más débil de la relación, lo que ciertamente deriva de la naturaleza del contrato de trabajo y del carácter de norma de orden público de protección ${ }^{33}$. En este sentido, e independientemente de la voluntad de las partes y del acuerdo civil o comercial que pueda existir entre la empresa principal y la contratista, se configura un vínculo entre la empresa principal y el trabajador, que convierte a la primera en un deudor más de la seguridad del trabajador $^{34}$.

Ahora bien, y como ya se ha advertido, esta obligación de la empresa principal deriva o se vincula en su extensión y magnitud a la obligación del artículo 184 del Código del Trabajo, impuesta por la ley y en su condición también de norma de orden público incorporada indisolublemente al vínculo contractual, constituyendo un elemento esencial del contrato de trabajo $^{35}$ y una obligación del mismo carácter, cuyo incumplimiento genera ciertamente responsabilidades tanto para el empleador, contratista o subcontratista, como para la empresa principal. En este sentido, entonces, el deber de seguridad, constituido en una obligación esencial del contrato de trabajo, se extiende a un tercero ajeno a la relación laboral, pero que, atendido el especial carácter de las normas de orden público que regulan la materia, irradian sus

\footnotetext{
${ }^{32}$ Molina con Comercial Sepmo y Cía. (2014).

${ }^{33}$ Ídem.

${ }^{3}{ }^{3}$ Ídem.

${ }_{35}$ Ídem.
} 
Paula E. Donoso Vergara / Aspectos de una relación triangular en la subcontratación laboral: Naturaleza jurídica y alcances de la obligación de cuidado de la empresa principal respecto de trabajadores de contratistas y subcontratistas que laboren en su obra o

efectos imponiendo a la empresa principal el cumplimiento de una obligación de naturaleza laboral, que, debido a su importancia y centralidad en el contrato de trabajo, le exigen una observancia completa, teniendo como máxima o guía el deber general de seguridad.

Dentro del marco antes analizado, corresponde ahora abordar los efectos que genera el incumplimiento de esta obligación por parte de la empresa principal, en cuanto al tipo de responsabilidad que surge para ésta y cómo se vincula con el régimen de responsabilidad general derivado del incumplimiento de las obligaciones laborales y previsionales de contratistas y subcontratistas.

\section{RESPONSABILIDAD DE LA EMPRESA PRINCIPAL ANTE EL INCUMPLIMIENTO DEL DEBER DE SEGURIDAD RESPECTO DE TRABAJADORES SUBCONTRATADOS}

\subsection{EL RÉGIMEN DE RESPONSABILIDAD DE LA EMPRESA PRINCIPAL RESPECTO DE OBLIGACIONES LABORALES Y PREVISIONALES DE SUS CONTRATISTAS Y SUBCONTRATISTAS. SUS LÍMITES Y EFECTOS}

Tal como se advirtió antes, uno de los elementos que permite afirmar la manifestación de un vínculo triangular entre la empresa principal, la contratista y el trabajador es la responsabilidad legal que se asigna a la primera respecto de las obligaciones laborales y previsionales de sus contratistas y subcontratistas en relación con los trabajadores subcontratados. Desde este punto de vista, quien se beneficia con los servicios de aquellos trabajadores se encuentra en el imperativo de responder ante el incumplimiento de tales obligaciones.

El régimen de responsabilidad que la Ley $N^{\circ} 20.123$ consagra para la empresa principal es el de responsabilidad solidaria, en relación con las obligaciones laborales y previsionales de dar, incluidas las obligaciones por término de la relación laboral. Así lo dispone el artículo 183 B del Código del Trabajo. No obstante, en cuanto al control sobre el cumplimiento de tales obligaciones, la empresa principal tiene la posibilidad de ejercer los derechos de información, de retención y pago por subrogación en los términos establecidos en el artículo $183 \mathrm{C}$ del Código del Trabajo. En tal caso, conforme lo señala el artículo $183 \mathrm{D}$ de este mismo cuerpo legal, la responsabilidad de la empresa principal - respecto de dichas obligaciones- pasaría a ser subsidiaria.

De esta manera, la responsabilidad inmediata de carácter solidaria que se establece para la empresa principal lleva implícita una garantía que busca asegurar el cumplimiento de los derechos de los trabajadores subcontratados, toda vez que el trabajador podrá demandar a la empresa principal, a la contratista y subcontratista, según corresponda, quienes deben responder indistintamente, por el cumplimiento de las obligaciones que se adeuden al trabajador $^{36}$. Salvo, como se señalaba, que este carácter solidario cambie por el accionar de la empresa principal, mediante el ejercicio de los derechos de información y retención, transformándose en tal caso en una responsabilidad de tipo subsidiario, en virtud de lo cual se deberá exigir el pago en primer lugar al contratista o subcontratista, según corresponda, esto es,

\footnotetext{
${ }^{36} \operatorname{ROJAS}(2011)$ p.157.
} 
Paula E. Donoso Vergara / Aspectos de una relación triangular en la subcontratación laboral: Naturaleza jurídica y alcances de la obligación de cuidado de la empresa principal respecto de trabajadores de contratistas y subcontratistas que laboren en su obra o

al empleador directo, y, en caso de no responder éste, se podrá exigir el pago a la empresa faena. principal.

Con todo, cabe advertir que esta responsabilidad queda limitada al período en que la empresa principal se ha beneficiado con los servicios prestados por el trabajador en régimen de subcontratación, esto es, no responde por aquellos períodos en que no ha estado vigente la relación que lo vincula de manera triangular con el trabajador ${ }^{37}$. Asimismo, la responsabilidad de la empresa principal queda restringida a las obligaciones de dar, excluyendo de esa manera las obligaciones de hacer. En tal sentido, la empresa principal no estaría compelida a responder en aquellos casos en que el incumplimiento de una obligación del contratista o subcontratista se traduce en un deber de ejecutar una acción determinada, como lo sería, por ejemplo, en el caso de exigirse la reincorporación de un trabajador o trabajadora protegido por fuero maternal o sindical ${ }^{38}$. Así, las obligaciones de dar con carácter laboral y previsional quedarían circunscritas a prestaciones tales como el pago de remuneraciones; las asignaciones en dinero, comprendiendo dentro de éstas a las percepciones compensatorias e indemnizatorias, prestaciones de seguridad social y beneficios sociales; las cotizaciones previsionales; y las indemnizaciones legales por término de contrato de trabajo ${ }^{39}$.

En otro orden de ideas, y como se adelantara, el trabajo en régimen de subcontratación admite relaciones en las que pueden intervenir más de tres partes. La vinculación puede ser cuadricular -cuando confluyen una empresa principal, una contratista, una subcontratista y los trabajadores de esta última- pudiendo incluso escalar a más subcontratistas, generando de tal modo una serie de relaciones sucesivas, sin que se contemple límite alguno por la ley en la generación de estas relaciones contractuales en cadena, y dando origen a lo que se ha denominado como una responsabilidad en cascada ${ }^{40}$. El artículo $183 \mathrm{~B}$ es amplio al señalar que la responsabilidad solidaria de la empresa principal se extenderá a las obligaciones que, en los mismos términos, afecten a sus subcontratistas. De esto se deriva que el trabajador puede exigir el cumplimento de una obligación adeudada a toda la cadena de empresas vinculadas entre sí por relaciones de tipo civil o comercial, llegando hasta la empresa principal.

No obstante lo anterior, según se ha dicho, un elemento que de algún modo permitiría deslindar responsabilidades para la empresa principal estaría determinado por sus posibilidades de ejercer fiscalización sobre la obligación incumplida, asunto que debería establecerse en cada caso de acuerdo con los elementos de hecho que lo definan ${ }^{41}$. En tal sentido, se ha sostenido que el problema a resolver en relación con esta exigencia estriba en la definición de los alcances de la posibilidad de fiscalizar ${ }^{42}$. Así, se ha concluido que en cualquier caso se requiere una participación activa de la empresa principal, en cuanto al ejercicio de este rol. En consecuencia, ella debe tomar todos los resguardos necesarios para evitar el incumplimiento y sólo en caso de un impedimento real de control y vigilancia podrá alegar tal imposibilidad de fiscalizar ${ }^{43}$. Este

\footnotetext{
${ }^{37}$ SALA et al. (2011), p.101.

${ }^{38}$ SALA et al. (2011) p.102.

${ }^{39}$ LIZAMA Y UGARTE (2009) p. 48.

${ }^{40}$ SALA et al. (2011) p.102.

${ }^{41}$ SALA et al. (2011) p.103.

42 RoJAs (2011) pp. 52-53.

43 Un aspecto relevante a considerar está dado por el lugar en el que ejecutan sus labores los trabajadores subcontratados. En tal sentido, a propósito de la discusión sobre la exigencia del elemento locativo para
} 
Paula E. Donoso Vergara / Aspectos de una relación triangular en la subcontratación laboral: Naturaleza jurídica y alcances de la obligación de cuidado de la empresa principal respecto de trabajadores de contratistas y subcontratistas que laboren en su obra o

problema ha sido examinado precisamente respecto del deber de seguridad en tanto obligación laboral del contratista o subcontratista, el que además impone una responsabilidad directa para la empresa principal que la obliga, como se señaló en el capítulo anterior, a la protección eficaz de la vida y salud de los trabajadores subcontratados ${ }^{44}$. Cómo se conjugan ambos esquemas de responsabilidad para la empresa principal, es un asunto complejo y que ha sido objeto de un amplio debate en la doctrina científica y la jurisprudencia.

\subsection{LA RESPONSABILIDAD DIRECTA DE LA EMPRESA PRINCIPAL RESPECTO DE LA OBLIGACIÓN DE CUIDADO Y SU VINCULACIÓN CON EL ESQUEMA DE RESPONSABILIDAD SOLIDARIA O SUBSIDIARIA DE LOS ARTÍCULOS 183- B Y 183-D DEL CÓDIGO DEL TRABAJO}

Al revisar el tema de la obligación directa y de naturaleza laboral que se impone a la empresa principal en materia de salud y seguridad respecto a los trabajadores subcontratados, se adelantó que el incumplimiento de esta obligación genera, a su turno, una responsabilidad directa para la empresa principal ante los eventuales daños que se provoquen al trabajador, conforme lo establece el artículo 183 E del Código del Trabajo, y que en tal virtud se establece un vínculo también directo que liga al trabajador con la empresa principal ${ }^{45}$. Esta fue una innovación introducida por la ley 20.123, mediante la cual se eleva a rango legal la obligación y responsabilidad de la empresa principal en cuanto a la seguridad y prevención de riesgos laborales respecto de todos los trabajadores que laboran en su obra o faena.

En el sentido antes indicado, esta responsabilidad de la empresa principal dice relación con una obligación genérica y amplia que debe asumir esta empresa, que incluye las medidas específicamente normadas para la prevención de riesgos, la obligación de vigilancia y todas aquellas que sean necesarias para la protección eficaz de la salud y seguridad de los trabajadores. Es decir, la empresa principal, en esta materia, no sólo está obligada a responder con su patrimonio ante los eventuales incumplimientos de la contratista o subcontratista que ocasionen daños a los trabajadores, sino que se genera al mismo tiempo una responsabilidad directa derivada de su propio incumplimiento y falta de diligencia.

Con todo, y conforme a lo que se ha señalado, resulta importante efectuar una distinción entre la existencia de una obligación y el imperativo de responder ante su incumplimiento. En la materia que nos ocupa el asunto se hace complejo, atendida la mencionada trilateralidad de la relación que se configura, que alcanza a la obligación y a la

\footnotetext{
determinar la existencia de trabajo en régimen de subcontratación, parte de la doctrina sostiene que este es un componente requerido por la ley, dado que los servicios deben prestarse en la empresa principal, mientras la doctrina mayoritaria rechaza tal afirmación indicando que lo relevante es el control, dirección u organización que posea la empresa principal sobre las labores contratadas. Véase: RoJAS (2010) p.198. De tal modo, estimamos que el criterio que debe predominar al respecto para los efectos de la imputación de responsabilidad asociada a dicho régimen está determinada por los elementos de control u organización de la actividad y no por el lugar en que se ejecutan las labores, en especial en lo referido a la seguridad de los trabajadores, donde pesa una especial obligación de vigilancia para la empresa principal.

${ }^{44}$ RoJAs (2011) pp. 52-53.

${ }^{45}$ En este trabajo se aborda sólo la responsabilidad derivada del incumplimiento que causa daños o perjuicios al trabajador y que obliga a la reparación de los mismos. De tal modo, no se revisa aquí la responsabilidad generada por la sola infracción de normas en materia de salud y seguridad que da lugar a la aplicación de multas administrativas por parte de los organismos públicos competentes. Tal dimensión, atendida su complejidad y las diversas aristas que comprende excedería el objeto de este estudio.
} 
Paula E. Donoso Vergara / Aspectos de una relación triangular en la subcontratación laboral: Naturaleza jurídica y alcances de la obligación de cuidado de la empresa principal respecto de trabajadores de contratistas y subcontratistas que laboren en su obra o

responsabilidad que emana de su eventual incumplimiento. Surgirá de este modo la responsabilidad tanto para la contratista o subcontratista como para la empresa principal en la medida que se verifique un accidente o enfermedad laboral que cause daño al trabajador. Lo que se demanda en tal caso es la indemnización de perjuicios, en el sentido de poner al trabajador en el estado anterior a la generación del daño ${ }^{46}$. En cuanto a la obligación de cuidado que se impone a la empresa principal, se ha establecido en esta investigación que ésta es de naturaleza laboral y de carácter directo. Esto es, existirían dos obligados respecto a la salud y seguridad del trabajador. Supuesto lo anterior, en cuanto a los obligados a responder por los daños causados y la forma en que estos responden han surgido diversas interpretaciones en la doctrina y la jurisprudencia nacional.

La principal dificultad que ha aparecido respecto a la interpretación de estas normas se relaciona con la forma en que se conjugan ambos esquemas de responsabilidad. Por una parte, la responsabilidad derivada de las obligaciones laborales y previsionales de dar de sus contratistas y subcontratistas y, por otra, la responsabilidad que surge del incumplimiento de la obligación de cuidado que se le impone directamente a la empresa principal. Esto ha sido determinante para establecer si la empresa principal y la contratista deben responder en forma simplemente conjunta, solidaria o subsidiaria ante los daños generados a los trabajadores subcontratados.

Sobre dicho punto la jurisprudencia judicial se ha pronunciado en forma contradictoria y cambiante, desde la entrada en vigencia de la ley 20.123. En este sentido, llama la atención la existencia de dos fallos recientes de unificación de jurisprudencia que se pronuncian en sentidos absolutamente contrapuestos y que dan cuenta de las dos principales soluciones que ha dado la jurisprudencia a este problema.

Una primera interpretación sostiene que el artículo 183 E del Código del Trabajo, al establecer una obligación particular y especial para la empresa principal, en materia de higiene y seguridad, excluye la aplicación del estatuto de responsabilidad solidaria del artículo $183 \mathrm{~B}$ del Código del Trabajo. De acuerdo con esta interpretación, el establecimiento de tal responsabilidad directa para la empresa principal supone determinar específicamente la conducta que por acción u omisión configuró un incumplimiento al deber que directamente se le impone y cómo éste se relaciona causalmente con los daños ocasionados. Se concluye, de este modo, que la empresa principal responde sólo por el incumplimiento de obligaciones propias y no como garante de las obligaciones que correspondan a sus contratistas o subcontratistas. En consecuencia, la forma en que las empresas deben cumplir la obligación de indemnizar los perjuicios ocasionados es simplemente conjunta, esto es, la obligación se divide entre ambos obligados y cada uno responde por su parte ${ }^{47}$.

Estimamos que una interpretación en el sentido antes indicado deja al trabajador, lisa y llanamente, en situación desmedrada, al tener que exigir separadamente a cada empresa el pago de la obligación de indemnizar los perjuicios derivados de accidentes o enfermedades laborales, y al excluir el estatuto de responsabilidad solidaria para la empresa principal. De ese modo, reduce el estándar de protección al trabajador en una materia sensible y respecto de una

46 Véase: BARRIENTOS (2012) pp. 77-111.

${ }^{47}$ Ramírez con Mena (2013); Aguayo con Ingeniería y Construcción Osarco E.I.R.L. (2014). 
Paula E. Donoso Vergara / Aspectos de una relación triangular en la subcontratación laboral: Naturaleza jurídica y alcances de la obligación de cuidado de la empresa principal respecto de trabajadores de contratistas y subcontratistas que laboren en su obra o

faena.

obligación central en la relación laboral, en un sentido claramente opuesto al espíritu de la modificación legal introducida por la Ley 20.123, cuya finalidad fue dar mayor intensidad al deber de protección, mediante el establecimiento de una obligación inmediata y una responsabilidad directa para la empresa principal en el ámbito de la salud y seguridad de los trabajadores subcontratados.

Una segunda interpretación de la jurisprudencia, en cambio, señala que para determinar el estatuto de responsabilidad del dueño de la obra se debe considerar en primer término el carácter tuitivo de las normas que regulan la materia y, en segundo término, el régimen de protección incorporado por la ley 20.123, que hace más exhaustiva la responsabilidad de la empresa principal en relación con los trabajadores subcontratados. Dicho esto, y establecida la naturaleza laboral de la obligación impuesta a la empresa principal, se sostiene que su carácter es contractual, entendido como una excepción al efecto relativo de los contratos. De tal modo, establece que si la ley ha previsto la solidaridad para la empresa principal ante los incumplimientos de las obligaciones laborales, entre las que está comprendido el deber de seguridad de la contratista, con mayor razón debe surgir este estatuto ante el incumplimiento de una obligación laboral directa que se impone a la empresa principal. Así, resultaría correcto establecer el carácter solidario de la responsabilidad de ambos obligados, sin que constituya un obstáculo a esa determinación la circunstancia de que el artículo 183 B del Código del Trabajo establezca dicho estatuto respecto a las obligaciones laborales de dar de los contratistas y subcontratistas, dado que, en último término, la obligación de indemnizar perjuicios convertiría al deber de cuidado en una obligación de tal carácter ${ }^{48}$.

Sobre la interpretación recién analizada, desde la doctrina civilista ${ }^{49}$ se ha formulado alguna crítica al argumento relativo a la transformación que experimentaría el deber de cuidado cuando se dispone el pago de una indemnización de perjuicios a su respecto, convirtiendo tal deber en una obligación de dar. Esta doctrina ha sostenido que dicho planteamiento va en contra de la categoría conceptual que divide en obligaciones de dar, hacer o no hacer. En definitiva, llevando el argumento al extremo, ha dicho que si se acepta tal interpretación sólo habría un tipo de obligaciones: todas serían obligaciones de dar ${ }^{50}$. Pese a que esta mirada comparte el criterio que descarta la existencia, en estos casos, de una obligación simplemente conjunta, no participa del carácter solidario que se le atribuye, y más bien apunta a la existencia de dos obligaciones independientes, pero que coinciden en su objeto, lo que daría lugar a obligaciones concurrentes ${ }^{51}$.

En un sentido diverso, la doctrina ha planteado que en los casos en que se persigue la responsabilidad de la empresa principal y la contratista, demandándola conjuntamente, la

\footnotetext{
${ }^{48}$ Molina con Comercial Sepmo y Cía. Ltda. (2014). Esta sentencia de la Cuarta Sala de la Corte Suprema fue acordada con una prevención de la Ministra Andrea Muñoz Sánchez, quien concurrió al fallo indicando que a su juicio "la fuente de la solidaridad que cabe aplicar al caso de autos se encuentra en el artículo 183-B del Código del Trabajo, desde que el hecho que la empresa principal tenga una responsabilidad directa (artículo 183-E del cuerpo legal citado) no significa otra cosa sino que se la pueda demandar independientemente del empleador directo, por su propia responsabilidad, lo que no elimina la solidaridad pasiva que la ley establece respecto de las obligaciones laborales que éste último haya adquirido, entre las que se cuenta la de indemnizar los perjuicios ocasionados por la infracción de su obligación de seguridad, contenida en el artículo 184 del Código del Trabajo". 49 Véase: CORRAL (2014)

${ }^{50}$ Ídem.

${ }^{51}$ Ídem.
} 
Paula E. Donoso Vergara / Aspectos de una relación triangular en la subcontratación laboral: Naturaleza jurídica y alcances de la obligación de cuidado de la empresa principal respecto de trabajadores de contratistas y subcontratistas que laboren en su obra o

faena.

dueña de la obra o faena, esto es, la empresa principal, se enfrenta a una doble responsabilidad: la que se le atribuye como responsable directo en virtud del artículo 183 E del Código del Trabajo y la que le asignan los artículos 183 B y 183 D en carácter de responsable solidario o subsidiario de las obligaciones de sus contratistas o subcontratistas ${ }^{52}$. De igual modo, se ha advertido sobre la necesidad de distinguir entre dos obligaciones de diversa naturaleza: la obligación preventiva y la indemnizatoria. En cuanto a la primera, la empresa principal es responsable por la protección eficaz de la salud y seguridad de los trabajadores en virtud a sus amplias obligaciones, sean estas exclusivas o compartidas con el contratista. En tal sentido, la obligación directa del artículo 183 E del Código del Trabajo impone a la empresa principal el cumplimiento de sus propias obligaciones y la vigilancia de las obligaciones del contratista, y para el caso que éstas últimas no se cumplan deberá la empresa principal adoptar las medidas necesarias y hacerse cargo directamente. Así, su naturaleza es la de una obligación de hacer. En lo que se refiere, en cambio, a la segunda obligación, la indemnizatoria, deriva del incumplimiento de las mencionadas obligaciones preventivas, el que genera en la mayoría de los casos una obligación pecuniaria por los daños producidos, constituyéndose de tal manera en una obligación de dar, lo que daría lugar a la aplicación del artículo 183 B del Código del Trabajo y a la responsabilidad solidaria de la empresa principal y el contratista ${ }^{53}$. Compartimos estas opiniones doctrinarias, toda vez que ellas dan cuenta de la mayor intensidad que se otorga a la protección de la vida y salud de los trabajadores subcontratados en la nueva normativa, y del establecimiento de una obligación y responsabilidad directa para la empresa principal, pero de cumplimiento solidario para ambos obligados, quienes deben responder por el total ante el trabajador.

\section{LA APLICACIÓN DE LOS PRINCIPIOS DEL DERECHO DEL TRABAJO EN LAS DEFINICIONES RELATIVAS A LA OBLIGACIÓN DE CUIDADO Y RESPONSABILIDAD DE LA EMPRESA PRINCIPAL}

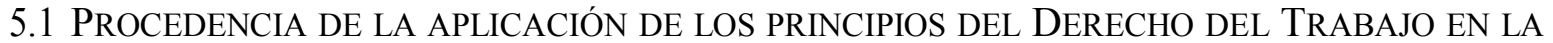 SOLUCIÓN DE LOS PROBLEMAS JURÍDICOS PLANTEADOS}

Como se indicó previamente, los problemas jurídicos que se han expuesto en esta investigación, en particular aquellos vinculados a la determinación de la naturaleza jurídica de la obligación de cuidado que se impone a la empresa principal y el estatuto de responsabilidad aplicable ante un incumplimiento que cause daño a los trabajadores subcontratados, pueden ser analizados bajo el prisma de los principios propios del Derecho del Trabajo. Esto, considerando especialmente que, según se ha establecido en este trabajo, en este aspecto estaríamos ante una vinculación triangular de tipo laboral, que involucra una obligación y responsabilidad de tal naturaleza.

En cuanto al rol de los principios, su relevancia está dada por su incidencia en la función de interpretación e integración de las normas del Derecho del Trabajo. En este sentido cumplen un papel fundamental en la aplicación de tal normativa y, según se ha sostenido, se constituyen en un puente entre la norma y la realidad normada. En cuanto a los problemas objeto de este análisis, la función interpretativa adquiere una relevancia especial, dado que, en tal

\footnotetext{
${ }^{52}$ En este sentido véase: GUMUCIO y SUSACASA (2011) pp. 81-86.

${ }^{53}$ NúÑEZ (2013) pp. 176-179.
} 
Paula E. Donoso Vergara / Aspectos de una relación triangular en la subcontratación laboral: Naturaleza jurídica y alcances de la obligación de cuidado de la empresa principal respecto de trabajadores de contratistas y subcontratistas que laboren en su obra o

dirección, los principios operan como criterios orientadores o argumentos para la justificación del intérprete. Esto, en todo caso, es aplicable en supuestos en que no existe claridad en cuanto al sentido y alcance de una norma ${ }^{54}$. En el ordenamiento jurídico laboral chileno la posibilidad de acudir a los principios del Derecho por parte de la judicatura laboral está expresamente reconocida en el artículo 459, numeral 5, del Código del Trabajo. No obstante, la manifestación de los principios jurídicos en las decisiones judiciales y la interpretación de normas que éstas llevan implícitas no constituyen una exigencia para la fundamentación. La motivación de las decisiones es una exigencia que se impone a los jueces y, en ese marco, tienen un amplio margen para acudir a diversos instrumentos y reglas de interpretación, entre los cuales sin lugar a dudas los principios -y en particular los propios del Derecho del Trabajocumplenuna función primordial.

Ahora bien, en este caso específico, la aplicación de los principios propios de la disciplina laboral se fundamenta plenamente, por los argumentos señalados previamente, en consideración a la materia de que se trata y a la naturaleza laboral, tanto de la obligación como de la responsabilidad asociada, a pesar de algunos intentos por conducir estas cuestiones hacia interpretaciones propias del Derecho Civil.

Pues bien, la jurisprudencia de los tribunales de justicia chilenos ha acudido a los principios del Derecho del Trabajo en la interpretación de las normas aplicables a los asuntos sometidos a su conocimiento y que dicen relación precisamente con la determinación del estatuto de responsabilidad aplicable a la empresa principal respecto de daños provocados a trabajadores subcontratados. Así las cosas, se ha sostenido específicamente que la aplicación de instituciones del Derecho Civil debe serlo bajo el prisma de los principios del Derecho del Trabajo $^{55}$. Específicamente, la interpretación que sostiene la responsabilidad solidaria de la empresa principal en tales casos acude al rol tuitivo de las normas laborales y al carácter protector del Derecho del Trabajo.

\subsection{LA APLICACIÓN DE LA REGLA INDUBIO PRO OPERARIO EN LA DETERMINACIÓN DEL ESTATUTO DE RESPONSABILIDAD APLICABLE A LA EMPRESA PRINCIPAL POR EL INCUMPLIMIENTO DEL DEBER DE SEGURIDAD QUE CAUSA DAÑO A TRABAJADORES SUBCONTRATADOS}

En cuanto al principio protector, considerado en la resolución de los problemas formulados, se ha dicho que éste opera como un criterio orientador indispensable que irradia a todo el derecho laboral. Esto derivado de la relación de desequilibrio existente entre las partes involucradas en la relación laboral y, en consecuencia, su finalidad no es la igualdad, sino establecer una situación de preferencia para una de las partes: el trabajador ${ }^{56}$. Este es un principio que se materializa en tres reglas: la in dubio pro operario, aplicable en caso de duda cuando la norma o situación específica puede ser entendida en sentidos diversos y se debe preferir la que más favorece al trabajador; la de la norma más favorable, en caso de que haya más de una norma que resuelva el asunto, debe optarse por la más favorable, aunque no sea la que corresponda según jerarquía; y la regla de la condición más beneficiosa, en virtud de la cual una

\footnotetext{
54 Véase: PALOMO (2007) pp. 63-64.

${ }_{55}$ Molina con Comercial Sepmo y Cía. Ltda. (2014).

56 LANATA (2010) pp. 47.
} 
Paula E. Donoso Vergara / Aspectos de una relación triangular en la subcontratación laboral: Naturaleza jurídica y alcances de la obligación de cuidado de la empresa principal respecto de trabajadores de contratistas y subcontratistas que laboren en su obra o

situación más beneficiosa anterior debe ser preferida a una nueva desfavorable para el faena. trabajador.

En cuanto a la primera de las reglas, la in dubio pro operario, se la ha denominado indistintamente como regla o principio. Pues, entendida como principio, obedece más bien a un criterio de interpretación, en el que no es posible la subsunción. De tal suerte, el carácter protector de las normas laborales, concebido de modo general, afecta el papel que juega el principio pro operario en su aplicación interpretativa para la solución de casos concretos. Esta peculiaridad del principio pro operario la distingue de las otras dos reglas señaladas. En tal sentido, uno de los cuestionamientos o dificultades que surgirían en torno a su rol interpretativo apunta a una posible pérdida de legitimidad y de recursos en la argumentación judicial, al acudir a un criterio que opera a favor de una de las partes: en este caso el trabajador. No obstante, cabe recordar, que la aplicación de este principio a casos concretos exige de parte del sentenciador la motivación de sus decisiones y la exposición de los razonamientos lógicos que conducen a una conclusión determinada. El principio protector $\mathrm{y}$, en particular, su manifestación como in dubio pro operario, debe utilizarse como una herramienta más de interpretación, que busca determinar el sentido y alcance de una norma legal en una situación determinada, y en ese orden constituye un instrumento válido y en ciertos casos necesario para la decisiónjudicial ${ }^{57}$.

En las aludidas interpretaciones, referidas a la determinación del estatuto de responsabilidad aplicable a la empresa principal por el incumplimiento del deber de seguridad que causa daño a trabajadores subcontratados, se ha acudido al denominado criterio pro operario, en virtud del cual se argumenta la integración de las normas que regulan la materia-las normas de los artículos 183 B y 183 E del Código del Trabajo- haciendo en concreto aplicable el estatuto de la responsabilidad solidaria, en virtud del cual ambos obligados, empresa principal y contratista, deben responder por el total de la obligación de indemnizar al trabajador, por los perjuicios causados a trabajadores subcontratados ${ }^{58}$.

El tal caso, la aplicación del principio pro operario se encuentra absolutamente justificada. Desde el punto de vista de su pertinencia, se trata de la interpretación de normas que además de encontrarse situadas espacialmente dentro de la normativa laboral, regulan obligaciones y responsabilidades de tal naturaleza que, como se ha visto, se dan en el marco de la mencionada trilateralidad laboral. En cuanto a la aplicación concreta del principio, estimamos que es correcta, dado que se trata de un caso de duda o ausencia de una norma específica que resuelva expresamente el asunto relativo al estatuto de responsabilidad para la empresa principal ante los daños ocasionados a trabajadores subcontratados. Por tal motivo, se acude al criterio pro operario, teniendo en cuenta, además del carácter protector general del Derecho del Trabajo, el sentido de unidad de sus normas y su especialidad.

De tal modo, la relación de doble vínculo que se verifica entre los intervinientes en el trabajo en régimen de subcontratación laboral debe ser observada, en su conjunto, desde la perspectiva de los principios del Derecho del Trabajo. Así las cosas, no obstante existir en estricto sentido, dos vínculos jurídicos distintos, uno de tipo comercial o civil que liga a la

\footnotetext{
57 Véase: RoJAS (2014) pp. 35-38.

${ }^{58}$ Molina con Comercial Sepmo y Cía. Ltda. (2014).
} 
Paula E. Donoso Vergara / Aspectos de una relación triangular en la subcontratación laboral: Naturaleza jurídica y alcances de la obligación de cuidado de la empresa principal respecto de trabajadores de contratistas y subcontratistas que laboren en su obra o faena. empresa principal con el contratista o subcontratista y otro de carácter puramente laboral que vincula -mediante un contrato de trabajo- al contratista o subcontratista con el trabajador, los principios de la disciplina laboral resultan igualmente aplicables en ambos sentidos y priman ante eventuales acuerdos o normas de carácter civil o comercial que se pretendan hacer valer en relación con las obligaciones y responsabilidades que surgen para la empresa principal respecto del trabajador subcontratado. De tal modo, los principios del Derecho del Trabajo además de afectar la interpretación normativa de la relación entre el trabajador y su empleador directo, inciden en la vinculación existente entre el trabajador subcontratado y la empresa principal, definiendo la forma en que esta última resulta obligada, el tipo de responsabilidad que se le asigna y cómo ésta debe hacerse efectiva.

\section{CONCLUSIONES}

En las páginas anteriores se ha tratado un problema jurídico que surge en el marco de la subcontratación laboral, el de la obligación de cuidado o deber de protección que la ley asigna a la empresa principal respecto de los trabajadores subcontratados. Al mismo tiempo, se ha dado cuenta de los efectos que se derivan de dicha obligación y de cómo se afecta en este aspecto a la institución de la contratación laboral. De este modo, el asunto es comprendido en el contexto de una relación de trabajo que se aleja de las formas típicas de contratación laboral, considerando la distancia existente entre el trabajador y la empresa que decide. El contrato de trabajo es celebrado entre el contratista y el trabajador; no obstante, las definiciones sobre dichas condiciones son tomadas en muchas ocasiones y en una medida importante por quien se beneficia con este trabajo: la empresa principal. Esto impacta de una manera especial en los aspectos relativos a la salud y seguridad de los trabajadores y, en tal sentido, la ley ha establecido una obligación directa para la empresa principal, la que debe hacerse cargo de adoptar medidas y responder ante eventuales resultados lesivos derivados de su incumplimiento.

De tal modo, el trabajo en régimen de subcontratación, en el ordenamiento jurídico chileno, se caracteriza por una relación de doble vínculo. De un lado, un contrato civil entre la empresa principal y la contratista y, de otro, un contrato de trabajo entre la contratista y el trabajador, sin que en principio exista relación inmediata entre la empresa principal y el trabajador. No obstante, la obligación de cuidado que impone la ley a la empresa principal derivada del contrato de trabajo existente entre el contratista y el trabajador- configuraría, al menos en este aspecto, una relación triangular de tipo laboral, quedando el trabajador ligado directamente tanto a su empleador directo, como a la empresa principal.

Así, la obligación que emerge para la empresa principal es de naturaleza laboral. Su fuente es doble, dado que es impuesta por la ley laboral en forma directa a la empresa principal y nace con el contrato de trabajo que se celebra entre el contratista y el trabajador, estableciendo de tal manera un vínculo directo con la empresa principal. Además, es una obligación genérica que obliga a la empresa principal a adoptar las medidas específicas que las normas legales y reglamentarias le asignan y todas aquellas necesarias para asegurar una protección eficaz, incluida la obligación de vigilar el cumplimiento de las exigencias legales que se establecen en esta materia para el contratista. En tal dirección, la ley 20.123 introdujo una importante modificación, generando en la práctica una deuda de seguridad con un acreedor, el trabajador y dos obligados, la contratista y la empresa principal. 
Asimismo, en lo que se refiere al tipo de responsabilidad que genera para la empresa principal el incumplimiento de la obligación de cuidado que le impone el artículo $183 \mathrm{E}$ del Código del Trabajo, y que causa daños al trabajador, se trata también de una responsabilidad de tipo laboral. La determinación de las específicas exigencias que impone la obligación de cuidado y el grado de responsabilidad que surge para la empresa principal en cuanto al cumplimiento del deber de protección, se encuentran marcados por el carácter tutelar del Derecho del Trabajo y, en tal sentido, corresponde la aplicación de los principios propios de esta disciplina. Ante las dudas existentes en cuanto a la naturaleza de tal obligación y al estatuto de responsabilidad aplicable -si ésta es solidaria o simplemente conjunta-, se sostiene que debe operar la responsabilidad solidaria, ya que este es el estatuto que la ley laboral establece para la empresa principal, respecto de las obligaciones laborales y previsionales de sus contratistas y subcontratistas, por aplicación del artículo 183 B del Código del Trabajo. Esta responsabilidad es directa para la empresa principal, pero de cumplimiento solidario, atendida la naturaleza laboral de la misma y debido a la existencia de una pluralidad de obligados respecto del acreedor. Esto, teniendo en cuenta la naturaleza laboral de la obligación de cuidado y el especial objeto de contratación en el trabajo en régimen de subcontratación.

De acuerdo a lo analizado, los efectos del contrato de trabajo, en este aspecto, se extienden a un tercero ajeno a la relación laboral. De tal modo, la empresa principal se encuentra legalmente obligada a adoptar todas las medidas relacionadas con el deber de protección, respecto de trabajadores, de sus contratistas y subcontratistas, generando su incumplimiento eventuales sanciones y responsabilidades de tipo laboral, por los resultados lesivos que ocasione.

Así las cosas, existe una relación triangular de tipo laboral entre la empresa principal, la contratista o subcontratista y el trabajador, en un aspecto central de la relación laboral, como lo es la obligación de protección eficaz de la salud y seguridad de los trabajadores. En tal sentido, se comprueba que además de manifestarse la trilateralidad laboral en la responsabilidad que se asigna a la empresa principal por las obligaciones laborales y previsionales de sus contratistas y subcontratistas, ésta se expresa de modo más intenso en cuanto a la obligación de cuidado que se le atribuye respecto de los trabajadores subcontratados, dado que le asigna el cumplimiento directo de una obligación preventiva y, a su turno, la obligación indemnizatoria por los efectos dañosos que se deriven de su incumplimiento. 


\section{BIBLIOGRAFÍA}

BARRIENTOS ZAMORANO, Marcelo (2012): "La obligación de seguridad en la subcontratación laboral: previsibilidad del hecho y del daño", Revista Chilena de Derecho (UC), vol. 39, º1, pp. 77-111.

CAAMAÑO ROJO, Eduardo (2005): "Las transformaciones del trabajo, la crisis de la relación laboral normal y del desarrollo del empleo atípico", Revista de derecho (Valdivia), vol. 18, №1, pp. 25-53.

CAAMAÑo Rojo, Eduardo (2007): "La Ley de Subcontratación y la tutela de los derechos fundamentales de los trabajadores de servicios transitorios", Ius et Praxis, vol. 13, N², pp. 157194.

CORRAL, Hernán (2014): "Subcontratación y responsabilidad civil por accidentes del trabajo" Disponible en: http://www.elmercurio.com/Legal/Noticias/AnalisisJuridico/2014/08/11/Subcontratacion-y-responsabilidad-civil-por-accidentes-del-trabajo.aspx

DIEZ SCHWERTER, José Luis (2008): "Responsabilidad civil derivada de accidentes del trabajo y enfermedades profesionales: Aspectos relevantes de su regulación y operatoria actual", Revista deDerecho de la Pontificia Universidad Católica de Valparaíso, Vol. XXXI,pp. 163-185.

ERMidA URIARTE, Oscar; COLOTUZzO, Natalia (2009): "Descentralización, tercerización, subcontratación" Disponible en: http://white.oit.org.pe/proyectoactrav/pry_rla_06_m03_spa/publicaciones/documentos/estu dio_descentralizacion_tercerizacion_subcontratacion.pdf

Gumucio Rivas, Juan Sebastián; Susacasa Massone, Javier (2011): "Examen de los regímenes de responsabilidad de la empresa principal en los siniestros profesionales sufridos por trabajadores de empresas contratistas y subcontratistas", Revista Laboral Chilena, $\mathrm{N}^{\circ} 4$, pp. 81-86.

LANATA FuENZALIDA, Gabriela (2010): Contrato individual de trabajo. (Santiago, Legal Publishing Chile, cuarta edición revisada y actualizada).

LizAMA PorTAL, Luis; UGARTE CATALDO, José Luis (2009): Subcontratación y suministro de trabajadores. (Santiago, Legal Publishing Chile, cuarta edición).

MATUS ORTEGA, Laura(2012): Responsabilidad de la empresa principal por accidentes del trabajo de los dependientes del contratista. Seminario de Titulación Magíster en Derecho del Trabajo y Seguridad Social. (Santiago, Universidad de Talca).

MElis VALENCIA, Christian; SÁEZ CARLIER, Felipe (2009): El contrato individual de trabajo en los dictámenes de la Dirección del Trabajo. (Santiago, Legal Publishing Chile, segunda edición). 
Paula E. Donoso Vergara / Aspectos de una relación triangular en la subcontratación laboral: Naturaleza jurídica y alcances de la obligación de cuidado de la empresa principal respecto de trabajadores de contratistas y subcontratistas que laboren en su obra o

NúÑEZ GONZÁlEZ, Cayetano (2013): Prevención de riesgos laborales en Chile: alcance y contenido del artículo 184 del Código del Trabajo. (Santiago, Chile, Librotecnia).

PALOMO VÉLEZ, Rodrigo (2007): "El rol de los principios en la aplicación del Derecho del Trabajo. Antecedentes conceptuales sobre el estado del arte en Chile", Revista Laboral Chilena, $\mathrm{N}^{\circ} 11$, pp. 59-69.

RASO DELGUE, Juan (2000): La contratación atípica del trabajo. (Montevideo, Editorial Amalio Fernández).

Rojas BalmaCEDA, Cristian (2014): El principio pro operario en el sistema jurídico chileno. Tesis de MagísterenDerecho del Trabajoy Seguridad Social.(Santiago, Universidadde Talca).

Rojas MiÑo, Irene (2004): Manual de Derecho del Trabajo. Derecho individual. (Santiago, Chile, Lexis Nexis).

ROJAS MiÑO, IRENE (2010): “La externalización laboral y la cesión ilegal de trabajadores en el sistema jurídico chileno”, Ius et Praxis, Vol. 16, №1, pp. 171-196.

Rojas MiÑo, Irene (2011): Subcontratación laboral, suministro de trabajo y cesión ilegal de trabajadores. (Santiago, Chile, Legal Publishing).

Sala Franco, Tomás; MANGarelli, Cristina; Omar García, Héctor y TAPIA Guerrero, Francisco (2011): La descentralización empresarial y la responsabilidad laboral en América Latina y España. (Valencia, TirantLoBlanch).

TAPIA GUERRERO, Francisco (2011): "Los Supuestos de subcontratación y suministro de mano de obra y las relaciones laborales aparente", Gaceta Jurídica, N³71, pp. 32-39.

Ugarte CATALDO, José Luis (2006): "Sobre relaciones laborales triangulares: La subcontratación y el suministro de trabajadores", Ius et Praxis, Vol. 12 N 1, pp. 11-29.

Ugarte Cataldo, José Luis (2011): El nuevo derecho del trabajo. (Santiago, Chile, Legal Publishing Chile, tercera edición).

\section{JURISPRUDENCIA JUDICIAL}

Ramírez con Mena (2013): Corte Suprema, 27 de marzo de 2013, Rol N 5620-2012 (acción de indemnización de perjuicios por accidente del trabajo) Disponible en: http://suprema.poderjudicial.cl/SITSUPPORWEB/InicioAplicacion.do [fecha de visita 15 de junio de 2015].

Aguayo con Ingeniería y Construcción Osarco E.I.R.L. (2014): Corte Suprema, 25 de febrero de 2014, Rol N 9858 - 2013 (acción de indemnización de perjuicios por accidente del trabajo) 
Paula E. Donoso Vergara / Aspectos de una relación triangular en la subcontratación laboral: Naturaleza jurídica y alcances de la obligación de cuidado de la empresa principal respecto de trabajadores de contratistas y subcontratistas que laboren en su obra o

Disponible en: http://suprema.poderjudicial.cl/SITSUPPORWEB/InicioAplicacion.do [fecha de visita 15 de junio de 2015].

Molina con Comercial Sepmo y Cía. (2014): Corte Suprema, 10 de junio de 2014, Rol N 10.139 2013 (acción de indemnización de perjuicios por accidente del trabajo), Disponible en: http://suprema.poderjudicial.cl/SITSUPPORWEB/InicioAplicacion.do [fecha de visita 15 de junio de 2015]. 